Doi: $10.32481 / \mathrm{djph} .2021 .12 .017$

\title{
Team Up For Quality Care:
}

\section{The Role of Primary Care Teams in Prevention Of Cardiovascular Disease}

\author{
Cindy Biederman, MSN, RN \\ Practice Transformation Specialist, Quality Insights
}

\begin{abstract}
Healthcare providers appreciate the value of evidence-based guidelines such as the American College of Cardiology/American Heart Association Guideline on the Primary Prevention of Cardiovascular Disease (Guideline). In a busy clinical practice, however, many competing demands can create barriers to full implementation of these protocols. A solution is to embrace a newer model of practice that engages the interdisciplinary care team with all staff working at the top of their licensure/training. The care team approach is backed by strong evidence supporting improved patient outcomes, such as hypertension control. By appropriately sharing responsibilities, the practice delivers a unified health promotion message, and physicians are able to focus on the care requiring their medical expertise. When all staff members have clear roles and responsibilities, the practice can more easily implement the Guideline fully and work together to deliver high-quality, evidence-based primary prevention of cardiovascular disease.
\end{abstract}

\section{Background}

Historically, preventive interventions have yielded improvements in population health. Such interventions largely fall to practitioners of primary care medicine, who must manage many competing demands. ${ }^{1}$ In recent years there has been a proliferation of clinical protocols and care guidelines intended to assist providers deliver evidence-based care, but implementation of these guidelines can be challenging for busy clinicians.

\section{Cardiovascular Disease Prevention}

Cardiovascular disease prevention is a high priority in primary care. According to the Centers for Disease Control and Prevention (CDC), heart disease is the leading cause of death for men, women, and people of most racial and ethnic groups in the United States. ${ }^{2}$ One in every four deaths in the U.S. is related to heart disease. In fact, an American dies from cardiovascular disease every 36 seconds, and about 655,000 Americans die from heart disease annually. According to a 2019 report from the Delaware Division of Public Health on chronic disease in Delaware, heart diseases represent $22 \%$ of all deaths annually. ${ }^{3}$ The impetus for prevention of these diseases is clear to society, the health system at large, and especially in primary care.

Hypertension is a major modifiable risk factor for cardiovascular disease. In the U.S., hypertension accounts for more cardiovascular disease deaths than any other modifiable risk factor. ${ }^{4}$ Improving hypertension control is a strategic pillar in national initiatives such as Million Hearts ${ }^{\circledR} 2022$ which aim to control hypertension in adults. While uncontrolled hypertension has improved significantly from 1999 to 2014, the burden remains high. ${ }^{5}$

Raised total cholesterol is another strong modifiable risk factor for cardiovascular disease. CDC reports that about $38 \%$ of adults have total cholesterol higher than $200 \mathrm{mg} / \mathrm{dl} .{ }^{2}$ In Delaware, about $35 \%$ of adults reported having high cholesterol in $2019 .{ }^{6}$ Strong evidence exists 
demonstrating the role of statin therapy risk reduction by lowering low-density lipoprotein cholesterol levels in diverse populations, yet it is estimated that only about half of the U.S. adults who could benefit from cholesterol medicine are currently taking it. ${ }^{2}$

\section{Guideline on the Primary Prevention of Cardiovascular Disease}

Since 1980, the American College of Cardiology (ACC) and American Heart Association (AHA) have translated scientific evidence into clinical practice guidelines with recommendations to improve cardiovascular health. The ACC/AHA Clinical Practice Guideline on the Primary Prevention of Cardiovascular Disease (Guideline) is based on systematic methods to evaluate and classify evidence and provide a foundation for the delivery of quality cardiovascular care. The purpose of the Guideline is to review and consolidate existing recommendations into a single guidance document focused on the primary prevention of cardiovascular disease (CVD). ${ }^{4}$

ACC/AHA describe the Guideline as a resource for the clinical and public health practice communities. It addresses the primary prevention of cardiovascular disease in adults over age 18 . The 2019 update (most recent available) includes new recommendations for aspirin use, exercise and physical activity and tobacco use, as well as recommendations related to shared decision making, assessment of social determinants of health, and team-based care. ${ }^{4}$ Appendix A provides the Guideline's Top Things to Know which summarizes the overarching recommendations in patient-centered approaches to prevention, assessment of cardiovascular risk, lifestyle factors, and other factors affecting risk. The Top Things to Know are categorized in Table 1 as HeartHealthy Lifestyles, Social Determinants of Health, and Risk Assessment/Pharmacotherapy.

Table 1. ACC/AHA Primary Prevention of Cardiovascular Disease - Top Things to Know, Categorized

\begin{tabular}{|l|l|}
\hline \multicolumn{1}{|c|}{ Category } & \multicolumn{1}{c|}{ Message } \\
\hline lifestyles & $\begin{array}{l}\text { The most important way to prevent atherosclerotic vascular disease, heart } \\
\text { failure, and atrial fibrillation is to promote a healthy lifestyle throughout life. }\end{array}$ \\
\cline { 2 - 3 } & $\begin{array}{l}\text { All adults should consume a healthy diet that emphasizes the intake of } \\
\text { vegetables, fruits, nuts, whole grains, lean vegetable or animal protein, and } \\
\text { fish and minimizes the intake of trans fats, red meat and processed meats, } \\
\text { refined carbohydrates, and sweetened beverages. For adults with overweight } \\
\text { and obesity, counseling and caloric restriction are recommended for achieving } \\
\text { and maintaining weight loss. }\end{array}$ \\
\cline { 2 - 3 } & $\begin{array}{l}\text { Adults should engage in at least 150 minutes per week of accumulated } \\
\text { moderate-intensity physical activity or 75 minutes per week of vigorous- } \\
\text { intensity physical activity. }\end{array}$ \\
\cline { 2 - 3 } & $\begin{array}{l}\text { All adults should be assessed at every healthcare visit for tobacco use, and } \\
\text { those who use tobacco should be assisted and strongly advised to quit. }\end{array}$ \\
\hline $\begin{array}{l}\text { Social } \\
\text { determinants } \\
\text { of health }\end{array}$ & $\begin{array}{l}\text { Clinicians should evaluate the social determinants of health that affect } \\
\text { individuals to inform treatment decisions. }\end{array}$ \\
\hline $\begin{array}{l}\text { Risk } \\
\text { assessment } \\
\text { and }\end{array}$ & $\begin{array}{l}\text { Adults who are 40 to 75 years of age and are being evaluated for } \\
\text { cardiovascular disease prevention should undergo 10-year atherosclerotic } \\
\text { cardiovascular disease (ASCVD) risk estimation and have a clinician-patient } \\
\text { risk discussion before starting on pharmacological therapy such as }\end{array}$ \\
\hline
\end{tabular}




\begin{tabular}{|l|l|}
\hline $\begin{array}{l}\text { Pharmaco- } \\
\text { therapy }\end{array}$ & $\begin{array}{l}\text { antihypertensive therapy, a statin, or aspirin. In addition, assessing for other } \\
\text { risk-enhancing factors can help guide decisions about preventive } \\
\text { interventions in select individuals, as can coronary artery calcium scanning. }\end{array}$ \\
\cline { 2 - 3 } & $\begin{array}{l}\text { For adults with type } 2 \text { diabetes mellitus, lifestyle changes such as improving } \\
\text { dietary habits and achieving exercise recommendations, are crucial. If } \\
\text { medication is indicated, metformin is first-line therapy, followed by } \\
\text { consideration of a sodium glucose cotransporter } 2 \text { inhibitor or a glucagonlike } \\
\text { peptide-1 receptor agonist. }\end{array}$ \\
\cline { 2 - 3 } & $\begin{array}{l}\text { Nonpharmacological interventions are recommended for all adults with } \\
\text { elevated blood pressure or hypertension. For those requiring } \\
\text { pharmacotherapy, the target blood pressure should generally be }<130 / 80 \text { mm } \\
\text { Hg. }\end{array}$ \\
\cline { 2 - 3 } & $\begin{array}{l}\text { Aspirin should be used infrequently in the routine primary prevention of } \\
\text { ASCVD because of lack of net benefits. }\end{array}$ \\
& $\begin{array}{l}\text { Statin therapy is first-line treatment for primary prevention of ASCVD in } \\
\text { patients with elevated low-density lipoprotein cholesterol levels (LDL-C) }(>= \\
190 \text { mg/dL), those with diabetes mellitus, who are } 40 \text { to } 75 \text { years of age, and } \\
\text { those determined to be at sufficient risk after a clinician-patient risk } \\
\text { discussion. }\end{array}$ \\
\hline
\end{tabular}

\section{The Vital Role of Primary Care}

In the expensive and specialized U.S. health system, primary care is the key to both increasing cost-effectiveness and providing foundational patient-centered care. The Agency for Healthcare Research and Quality (AHRQ) describes high-quality primary care as first-contact/accessible; coordinated; continuous; and comprehensive. ${ }^{7}$

High quality primary care services optimize patient health in a cost-effective manner. This vital role will continue to grow as the U.S. population ages and the prevalence and complexity of chronic disease increases. ${ }^{7}$ High-performing primary care engages well-organized, multidisciplinary practice teams to deliver comprehensive, evidence-based services. Examples include identification of potential care gaps, medication management, referral/transition management, and clinic/community linkages. ${ }^{8}$

\section{Team-Based Care}

The American Medical Association (AMA) defines team-based care as a collaborative system in which team members share responsibilities to achieve high-quality patient care. AMA believes that physician-led teams of multidisciplinary health care professionals should involve collaboration and sharing decisions and information for the benefit of patients. Members of the care team should work together depending on the specific training and strengths of each member. ${ }^{9}$ In the most effective teams, individuals are encouraged to utilize their full skill set to enhance patient care and increase effectiveness and efficiency. ${ }^{10}$

Well-implemented team-based care can improve comprehensiveness, coordination, efficiency, effectiveness, and value of care, as well as satisfaction of patients and providers. Team-based care offers expanded access and more effective and efficient delivery of essential services, such as patient education, behavioral health, self-management support, and care coordination. Patientcentered care is linked to improved physician-patient communication and relationships, higher 
patient satisfaction, improved recall of information and treatment adherence, better recovery, and improved health outcomes. ${ }^{10}$

Team-based care benefits providers and other members of the care team as well as their patients. A 2018 National Academy of Medicine discussion paper, Implementing Optimal Team-Based Care to Reduce Clinician Burnout, highlights a number of studies demonstrating strong evidence in support of high-functioning teams and their link to increased physician well-being as well as cost-effectiveness. ${ }^{11}$ Promoting a strong sense of team unity and collective responsibility for patient care can benefit every member of the staff, both clinical and clerical. All members of the team can view themselves as important contributors with a crucial role in promoting patient health. ${ }^{8}$

\section{Core and Extended Teams in Primary Care}

In primary care, a team is the providers and staff in a practice that collaborate to provide care to a defined panel of patients. ${ }^{8}$ It includes engaged, strong leadership and both core staff who work primarily with individual providers or a small group of providers and patients and an extended team of centralized staff that serve all providers and panels in the practice. The extended team might also include collaborating organizations such as pharmacists, academic institutions, and community agencies. Large or health system-affiliated practices may have greater access to extended contributors such as social workers, dieticians, care coordinators, and health educators, while smaller practices often leverage the skills of internal staff and external community resources to fill these roles.

The role of the physician as the leader of the health care team is important. Physicians have the highest level of training in patient care and often set the agenda for the practice. ${ }^{9}$ Physician leaders must review and approve clinical protocols, workflow modifications, staff training, and patient education resources. As engaged leaders, they must be committed to improving their care teams. In this practice model, every member of the team is recognized and valued for their skills and contributions, enabling the practice to support unified implementation of quality care.

Healthy care teams exhibit common traits including shared goals, clear roles, mutual trust, effective communication, and measurable processes and outcomes. ${ }^{8}$ Individual care teams are unique in team member disciplines and training, preferred communication styles, patient populations, and personalities. The workflow modifications discussed in this document should be considered as examples that must be adapted to individual settings.

\section{Role of the Patient}

In patient-centered care, patients and their families are key parts of the care team and contribute to decision making. Patients partner with trusted healthcare providers, and patient and family preferences, values, cultural traditions, and socioeconomic conditions are respected. ${ }^{8}$ Providers use diverse strategies, including technology-based tools, to empower patients to take ownership of their health care outside the clinical setting.

Patients benefit from this model are reflected in higher satisfaction scores, improved selfmanagement and adherence to treatment plans, increased morale and productivity of clinicians and ancillary staff, and better resource allocation. ${ }^{12}$ 
Patients are the core of high-quality primary care ${ }^{8}$ including primary prevention of cardiovascular disease. While not specifically identified in the workflow modifications presented in this document, patients are team members around whom all recommendations revolve.

\section{Technology as Care Team Support}

The proliferation of electronic health records (EHRs) and health information exchanges (HIEs) in recent years creates both demands on and opportunities for clinicians. Many feel that documentation creates barriers to relationship development when providers appear more focused on screens than on patients. ${ }^{13}$ However, strategic use of the EHR can create efficiencies that free up provider time. Practices should utilize the many tools at their disposal with most modern EHRs, such as patient portals, the ability to create registries for priority areas of care, clinical decision support systems to enhance decision making, and structured data fields that facilitate the documentation process, consulting individual EHR vendors for specific guidance.

\section{Care Teams: Primary Prevention of Cardiovascular Disease}

The 2019 update of the ACC/AHA Guideline on the Primary Prevention of Cardiovascular Disease promotes team-based care supports such as clinical decision making based on treatment algorithms, collaboration among different clinicians, and patient and family member participation to facilitate treatment goals. ${ }^{4}$ Randomized control trials and systematic reviews with meta-analyses demonstrated greater risk reduction with team-based care than usual care in patients with hypertension, diabetes and hyperlipidemia. Appendix B provides an example of improved blood pressure control attributable to team-based care. Further, a team-based approach may result in significant improvements in patient outcomes and often meets patient needs better than standard care, especially in low-resource settings and among vulnerable populations. ${ }^{4}$

The Guideline recommendations address both universal health measures such as diet and exercise and specific cardiac risk factors including tobacco use, hypertension, and cholesterol. ${ }^{4}$ To fully integrate and implement the Guideline's Top Things to Know primary prevention strategies in a primary care practice, every member of the core and extended care team can creatively and effectively play a role.

\section{Heart-Healthy Lifestyle Recommendations}

The Guideline recommends that every patient visit start by promoting primary prevention of cardiovascular disease. Two of the Top Things to Know advocate for prevention of cardiovascular disease by providing direction on heart-healthy diets, including achieving and maintaining normal weight, and physical activity recommendations. ${ }^{4}$ These universal, important messages can and should be shared and reinforced by every member of the practice team, from the front desk to the physician, in order to present a strong, unified message of health promotion and disease prevention.

\section{Heart Healthy Diets}

After four decades of decline, heart disease deaths rose by $1 \%$ in 2015 , a trend that may be attributable to the obesity epidemic. ${ }^{14}$ Therefore all patients should receive guidance about hearthealthy diets. Those with overweight or obesity should be encouraged to attain clinically meaningful weight loss ( $>=5 \%$ of initial weight), which is associated with moderate 
improvement in blood pressure, LDL-C, triglycerides, and glucose levels as well as reducing or delaying development of type 2 diabetes. $^{4}$

The Guideline states that existing clinical guidance strongly recommends face-to-face or telephonic weight loss programs that provide regular contact with a trained interventionist. ${ }^{4}$ Patients who need assistance with weight management can be referred to a nutritionist or to appropriate evidence-based lifestyle change programs, such as WW (Weight Watchers) or the National Diabetes Prevention Program.

Patient education materials on heart-healthy diet and physical activity recommendations, available from sources such as AHA and CDC, are the starting point for implementing lifestyle messaging. Materials can be made available in various locations in the medical office such as waiting areas and exam rooms and can be used by clinicians as conversational guides. These materials should address healthy weight, blood cholesterol levels, and blood pressure. Appendix C provides examples of resources.

\section{Physical Activity}

Regular exercise is known to confer numerous health benefits, and physical activity is a cornerstone of maintaining and improving cardiovascular disease. However, approximately half of adults in the U.S. do not meet the minimum physical activity recommendations. ${ }^{4}$

Physical activity assessment and counseling in the healthcare setting have important complementary roles in promoting increased compliance. Ascertaining physical activity patterns during a standard clinical visit is a first step in effective counseling. This data can be collected during patient rooming and recorded in the EHR along with parameters such as weight and blood pressure. ${ }^{4}$ Counseling by clinicians can result in modest improvement in physical activity levels and might include an exercise prescription that consists of recommended frequency, intensity, time (duration), and type of exercise. ${ }^{15}$

\section{Tobacco Screening and Cessation}

Since tobacco use is the leading preventable cause of disease, disability, and death in the United States, clinicians should ask all adults about tobacco use at every visit. ${ }^{16}$ Treating tobacco use status as a vital sign and recording it in the health record not only increases the rate of tobacco treatment but also improves abstinence. Tobacco users are more likely to quit after six months when clinicians strongly advise adults to quit, compared to no advice or usual care. ${ }^{16}$ For tobacco cessation, multiple behavioral interventions and seven FDA-approved cessation medications exist. Patients can be referred for telephonic or text-message counseling. Appendix $\mathrm{C}$ provides examples of resources.

Suggested workflows for care team roles and responsibilities for heart-healthy lifestyle recommendations are presented in Table 2.

Table 2. ACC/AHA Primary Prevention of Cardiovascular Disease Recommendations Suggested Care Team Roles and Responsibilities for Heart-Healthy Lifestyles
Team Up Actions
Members/Roles 


\begin{tabular}{|c|c|}
\hline Administrative staff & $\begin{array}{l}\text { - Ensure selected educational resources available in paper or } \\
\text { electronic (patient portal) form } \\
\text { - Track quality measures and share with staff } \\
\text { - Ensure all staff is trained in health promotion messaging and } \\
\text { evidence-based lifestyle programs } \\
\text { - Provide staff training on BP measurement techniques }\end{array}$ \\
\hline Front office & $\begin{array}{l}\text { - Disseminate selected resources to patients at check-in } \\
\text { - Schedule follow-up appointments for office and to community } \\
\text { programs } \\
\text { - Ensure information about evidence-based lifestyle programs is } \\
\text { readily available }\end{array}$ \\
\hline MAs and/or nurses & $\begin{array}{l}\text { - Assess and document BMI, tobacco use, and physical activity } \\
\text { level } \\
\text { - Query patient about concerns; share with provider } \\
\text { - Provide information on evidence-based programs for weight } \\
\text { management and tobacco cessation } \\
\text { - Ensure referrals made to provider-recommended programs }\end{array}$ \\
\hline Provider & $\begin{array}{l}\text { - Select educational resources and evidence-based lifestyle } \\
\text { change programs } \\
\text { - Counsel on healthy diet and physical activity; emphasize value } \\
\text { of lifestyle change } \\
\text { - Provide brief intervention/counsel on tobacco cessation } \\
\text { - Recommend evidence-based lifestyle change programs } \\
\text { - Discuss patient concerns and respond to questions }\end{array}$ \\
\hline
\end{tabular}

\section{Social Determinants of Health}

According to the $\mathrm{CDC}$, social determinants of health $(\mathrm{SDOH})$ are the conditions in the places where people live, learn, work and play, that affect a wide range of health risks and outcomes. These factors exist "upstream" in that they occur and inter-relate with each other to influence characteristics that manifest "downstream," such as health behaviors, health conditions, and health outcomes. ${ }^{17}$ While primary care providers and care teams are essential to optimizing health for their patients by providing evidence-based, patient-centered care in medical homes, most providers are well aware of the impact of SDOH on their patients. In fact, the Robert Wood Johnson Foundation estimates that only $20 \%$ of health outcomes can be attributed to clinical care, with the remaining $80 \%$ attributable to upstream factors such as social and economic factors and health behaviors. ${ }^{18}$

Although social determinants are most often invoked in discussions of inequalities or disparities in health, AHA takes a broader view that social factors can and do affect cardiovascular health. AHA acknowledges the evidence of association of early-life socioeconomic factors on the development of conventional cardiovascular disease risk factors, such as blood pressure, lipid levels, BMI, smoking, physical activity, and alcohol consumption. The organization's 2030 U.S. impact goal to equitably increase healthy life expectancy includes an emphasis on health equity. ${ }^{19}$ 
When care teams collect SDOH data such as housing status and food security, they get a clearer picture of the needs of their patients both individually and as a population. As the AMA points out, "Ensuring patients get equitable care is difficult if you aren't sure who your patients really are." 20 The AMA's Commission to End Health Care Disparities is investigating best practices in collecting race, ethnicity and preferred language data from patients in ambulatory settings with the goal of integrating services to meet identified needs of patients. Primary care providers can help their patients and communities achieve improved outcomes by serving as integrators among clinical care, public health, behavioral health, and community-based services. ${ }^{20}$

Getting started with $\mathrm{SDOH}$ is a valuable but complex project for a busy practice. Involving the full staff is integral, with both clinical and non-clinical staff needed to optimize processes. Data can be collected in a number of ways, at the point in the workflow and by the staff members deemed most appropriate. Systemizing the process begins by defining clear guidelines on roles and responsibilities. ${ }^{21}$

Organizations may wish to consider adopting a standardized, validated tool for collecting SDOH data, such as Protocol for Responding to and Assessing Patients' Risks and Experiences (PRAPARE). ${ }^{21}$ By using PRAPARE, providers can better target clinical and non-clinical care, often in partnership with other community based organizations, to drive care transformation and delivery system integration as well as improved health and cost reductions. ${ }^{21}$

According to the American Hospital Association, the ICD-10 code system is a tool for capturing data on the social needs of patients. ${ }^{22}$ Codes Z55-65 document non-medical factors that may influence a patient's health status. These $Z$ codes identify issues related to a patient's socioeconomic situation, including education and literacy, employment, housing, lack of adequate food or water or occupational exposure to risk factors such as dust, radiation, or toxic agents. Using these $\mathrm{Z}$ codes allows for better tracking needs and identification of solutions to improve community health. ${ }^{22}$

The American Hospital Association notes that any clinician involved in a patient's care can document a patient's social needs, according to a 2018 coding rules clarification. "Clinician" is defined as anyone who meets the requirements to document in the official medical record, including but not limited to social workers, community health workers, case managers, nurses, or other providers. $^{22}$

Assessing and addressing social determinants of health are important to comprehensive patient care, including primary prevention of cardiovascular disease. It is important to achieve buy-in from the full staff and to share responsibilities appropriately. Suggested workflows for care team roles and responsibilities for social determinant of health recommendations are presented in Table 3.

Table 3. ACC/AHA Primary Prevention of Cardiovascular Disease Recommendations Suggested Care Team Roles and Responsibilities for Social Determinants of Health

\begin{tabular}{|l|l|}
\hline $\begin{array}{l}\text { Team Up } \\
\text { Members/Roles }\end{array}$ & Actions \\
\hline Administrative staff & $\begin{array}{l}\text { - Support integration of SDOH tools into EHR } \\
\text { - Train staff about SDOH } \\
\text { - Track data for evaluation } \\
\text { - Communicate outcomes to team }\end{array}$ \\
\hline
\end{tabular}




\begin{tabular}{|c|c|}
\hline Front office & $\begin{array}{l}\text { - Disseminate paper or electronic materials to patients } \\
\text { via portal or mail } \\
\text { - Provide assessment materials at check-in } \\
\text { - Collect race, ethnicity, and language at check-in } \\
\text { registration } \\
\text { - Ensure data entered into EHR; alert clinical staff as } \\
\text { needed } \\
\text { - Maintain resource lists and provide to patients }\end{array}$ \\
\hline MAs and/or nurses & $\begin{array}{l}\text { - Verbally interview patients and enter responses into } \\
\text { EHR } \\
\text { - Discuss patient needs and assess for readiness to } \\
\text { address } \\
\text { - Discuss community resources and schedule per } \\
\text { practice workflow } \\
\text { - Enter Z codes into patient record (social needs codes } \\
\text { Z55-Z65 can be entered by any clinician involved in } \\
\text { patient's care) } \\
\text { - Follow up on referrals }\end{array}$ \\
\hline Provider & $\begin{array}{l}\text { - Select assessment tool; determine workflow } \\
\text { - Verbally interview patients and enter responses into } \\
\text { EHR } \\
\text { - Refer patients to other team members for supplemental } \\
\text { counseling, using warm handoff where possible }\end{array}$ \\
\hline
\end{tabular}

\section{Risk Assessment and Pharmacotherapy}

Assessment of risk is the foundation of primary prevention of cardiovascular disease and is a key domain of medical providers. ${ }^{4}$ The ten-year risk estimate is used to guide decision making for many preventive interventions, including lipid and blood pressure management. It should be the start of a conversation with the patient about risk reduction strategies and one decision factor for the initiation of pharmacotherapy. For patients with borderline or intermediate estimated 10-year risk, assessment of coronary artery calcium is a tool to reclassify risk either upward or downward. ${ }^{4}$ The American College of Cardiology's ASCVD Risk Estimator Plus is recommended for assessing a patient's ten-year risk and is available online or in a dedicated app. ${ }^{4}$

Initiation of pharmacotherapy, such as aspirin, antihypertensives, or statins is the role of the provider using clinical judgment of individual patients' unique needs. Aspirin was previously recommended for selected primary prevention for adults with elevated risk based on traditional factors, but the updated Guideline recommends that low-dose prophylactic aspirin be used for persons at high ASCVD risk who cannot achieve optimal control of other risk factors. Providers must evaluate use of aspirin therapy based on individual patient considerations. ${ }^{4}$

\section{Undiagnosed Hypertension}

A priority area of the Million Hearts ${ }^{\circledR}$ initiative is identifying patients with undiagnosed hypertension. ${ }^{23}$ Million Hearts ${ }^{\circledR}$ estimates that one in three U.S. adults (approximately 71 million people) has high blood pressure, and almost half of these individuals (48.2\%) do not 
have their condition under control. Closer examination of the population with uncontrolled hypertension reveals that $36.2 \%$ (estimated at approximately 13 million people) are neither aware of the condition nor taking antihypertensive medications. The majority of these individuals have health insurance, a usual source of care, and have received care two or more times in the past year. ${ }^{23}$ The care team can play a valuable role in addressing undiagnosed hypertension using the process and tools created by Million Hearts ${ }^{\circledR}$, such as searching the EHR for patients who meet the clinical criteria and calculating the practice's hypertension prevalence compared with local data.

\section{Hypertension Control (including Self-Measured Blood Pressure)}

A Community Guide Systematic Review found that team-based care is effective for improving blood pressure outcomes, including reducing both systolic and diastolic pressures, especially when pharmacists and nurses were part of the care team. ${ }^{24}$ Appendix B shows examples of changes in proportion of patients with controlled blood pressure attributable to team-based care.

The CDC promotes team-based care to improve blood pressure control and cites evidence supporting strong effectiveness of a multidisciplinary team working in collaboration to educate patients, identify risk factors, prescribe and modify treatments, and maintain an ongoing dialog with patients about their health and care. These teams may include doctors, nurses, pharmacists, primary care providers, community health workers, and others. Team-based care is a costeffective strategy for increasing medication adherence and lowering blood pressure among diverse populations in various settings. Suggested strategies include use of registries and leveraging EHRs to improve patient-provider communication. ${ }^{25}$

Nonpharmacological interventions are effective in lowering blood pressure and may be sufficient to prevent hypertension and to achieve goal measures in some individuals, and they are integral in the management of those on antihypertensive medications. Combining nonpharmacological interventions is the preferred therapy for adults with elevated blood pressure and an appropriate first-line therapy for adults with stage one hypertension who have an estimated 10-year ASCVD risk of $<10 \%$. The Guideline provides recommendations for assessing adherence to and impact of nonpharmacological therapy within three to six months as well as recommended goals and approximate impact on systolic blood pressure. ${ }^{4}$

Strong scientific evidence shows that self-measured blood pressure monitoring (SMBP) plus clinical support helps people with hypertension lower their blood pressure. ${ }^{26} \mathrm{SMBP}$ plus clinical support can improve access to care and quality of care for individuals with hypertension while making blood pressure control more convenient and accessible to patients. Clinical support includes regular one-on-one counseling, web-based or telephonic support tools, and educational classes. For patients with hypertension, the practice can implement SMBP, as recommended by Million Hearts ${ }^{\circledR}{ }^{26}$ Staff members can educate patients about blood pressure, train on accurate measurement technique, maintain the SMBP registry, and document measurements for providers.

Appendix $\mathrm{C}$ shows examples of resources that can be integrated in many workflows.

\section{Statin Therapy}

Statin therapy is first-line treatment for primary prevention of cardiovascular disease in patients with elevated low-density lipoprotein cholesterol levels ( $>190 \mathrm{mg} / \mathrm{dL})$, those ages 40-75 who have diabetes, and those determined to be at sufficient risk after a clinician-patient risk 
discussion. A useful tool is the Statin Choice Decision Aid, which can be administered by the provider, a nurse, health educator, or pharmacist. ${ }^{27}$

\section{Medication Adherence}

Medication adherence is a long-recognized challenge with costly impacts. Million Hearts ${ }^{\circledR}$ relates that about $20-30 \%$ of prescriptions are unfilled and another $50 \%$ of patients discontinue the prescribed treatment regimen. ${ }^{28}$ The Adherence Estimator ${ }^{\circledR}$, which can be administered by any clinician and shared with the provider, is a patient-centered resource designed to help gauge a patient's likelihood of adhering to newly prescribed oral medication for certain chronic, asymptomatic conditions, such as high cholesterol. Patients respond to three quick statements that provide a score indicating the probability of medication nonadherence, with conversational prompts that guide the provider to explore and address potential barriers. ${ }^{29}$

While a pharmacist may not be an existing part of the practice core team, providers in Delaware can take advantage of collaboration through a Delaware Division of Public Health/Delaware Pharmacists Society program that provides no-cost medication therapy management for patients taking antihypertensive and cholesterol- lowering medications. ${ }^{30}$

Suggested workflows for care team roles and responsibilities for risk assessment/ pharmacotherapy recommendations are presented in Table 4.

Table 4. ACC/AHA Primary Prevention of Cardiovascular Disease Recommendations Suggested Care Team Roles and Responsibilities - Risk Assessment/Pharmacotherapy

\begin{tabular}{|c|c|}
\hline $\begin{array}{l}\text { Team } \\
\text { Members/Roles }\end{array}$ & Actions \\
\hline $\begin{array}{l}\text { Administrative } \\
\text { staff }\end{array}$ & $\begin{array}{l}\text { - Search EHR to identify patients with possible undiagnosed } \\
\text { hypertension } \\
\text { - Maintain registry of patients with diagnosed hypertension } \\
\text { and elevated cholesterol } \\
\text { - Coordinate SMBP program } \\
\text { - Track data for evaluation and share with staff }\end{array}$ \\
\hline $\begin{array}{l}\text { MAs and/or } \\
\text { nurses }\end{array}$ & $\begin{array}{l}\text { - Provide patient education on hypertension, elevated } \\
\text { cholesterol, and medication adherence } \\
\text { - Assist patients with Statin Choice decision aid } \\
\text { - Perform medication reconciliation; explore barriers and } \\
\text { communicate to provider } \\
\text { - Provide nurse appointments for blood pressure monitoring } \\
\text { - Facilitate SMBP, train patients on techniques }\end{array}$ \\
\hline
\end{tabular}




\begin{tabular}{|l|l|}
\hline Provider & • Establish criteria to identify undiagnosed/uncontrolled \\
hypertension \\
- Recommend self-measured blood pressure monitoring \\
- Risk-benefit discussions when initiating pharmacotherapy \\
- When initiating pharmacotherapy, administer Adherence \\
Estimator to assess for medication adherence; discuss \\
results \\
- Use risk estimation and decision aid tools \\
- Initiate and monitor pharmacotherapy as clinically \\
appropriate \\
- Collaborate with pharmacist with referring eligible patients \\
for medication therapy management \\
\hline
\end{tabular}

\section{Conclusion}

Cardiovascular disease is the leading cause of death in the United States ${ }^{2}$ and the second leading cause of death in Delaware. ${ }^{3}$ Primary care providers, highly engaged in care for cardiovascular and other diseases as well as regular preventive care, must contend with the rapidly changing healthcare landscape that makes it difficult to manage a patient population and fully implement evidence-based protocols such as the ACC/AHA Guideline on the Primary Prevention of Cardiovascular Disease. Team-based models of primary care engage the interdisciplinary team with members working at the top of licensure/training to support providers and patients. When all staff members have clear roles to play, the practice can more easily fully implement the Guideline and work together to deliver high-quality, evidence-based primary prevention of cardiovascular disease.

\section{Disclosure}

This publication was supported by the Cooperative Agreement Number NU58DP006516 from the Centers for Disease Control and Prevention. Its contents are solely the responsibility of the authors and do not necessarily represent the official views of the Centers for Disease Control and Prevention. Publication number DEDPH-HD-041321A

Ms. Biederman can be contacted at cbiederman@qualityinsights.org

\section{Appendix A.}

\section{ACC/AHA Guideline on Primary Prevention of Cardiovascular Disease: Top Things to Know ${ }^{31}$}

1. The most important way to prevent atherosclerotic vascular disease, heart failure, and atrial fibrillation is to promote a healthy lifestyle throughout life.

2. A team-based approach is an effective strategy for the prevention of cardiovascular disease. Clinicians should evaluate the social determinants of health that affect individuals to inform treatment decisions.

3. Adults who are 40 to 75 years of age and are being evaluated for cardiovascular disease prevention should undergo 10-year atherosclerotic cardiovascular disease (ASCVD) risk estimation and have a clinician-patient risk discussion before starting on pharmacological 
therapy, such as antihypertensive therapy, a statin or aspirin. In addition, assessing for other riskenhancing factors can help guide decisions about preventive interventions in select individuals, as can coronary artery calcium scanning.

4. All adults should consume a healthy diet that emphasizes the intake of vegetables, fruits, legumes, nuts, whole grains, lean vegetable or animal protein, and fish and minimizes the intake of trans fats, processed meats, refined carbohydrates, and sweetened beverages. For adults with overweight/obesity, comprehensive lifestyle interventions, including counseling and caloric restriction, are recommended for achieving and maintaining weight loss.

5. Adults should engage in at least 150 minutes per week of accumulated moderate-intensity physical activity or 75 minutes per week of vigorous-intensity physical activity.

6. For adults with type 2 diabetes mellitus, lifestyle changes, such as improving dietary habits and achieving exercise recommendations, are crucial. If medication is indicated, metformin is first-line therapy, followed by consideration of a sodium-glucose cotransporter 2 inhibitor or a glucagon-like peptide-1 receptor agonist.

7. All adults should be assessed at every healthcare visit for tobacco use, and those who use tobacco should be assisted and strongly advised to quit.

8. Aspirin should be used infrequently in the routine primary prevention of ASCVD because of lack of net benefit.

9. Statin therapy is first-line treatment for primary prevention of ASCVD in patients with elevated low-density lipoprotein cholesterol levels (>190 mg/dL), those with diabetes mellitus, who are 40 to 75 years of age, and those determined to be at sufficient ASCVD risk after a clinician-patient risk discussion.

10. Nonpharmacological interventions are recommended for all adults with elevated blood pressure or hypertension. For those requiring pharmacological therapy, the target blood pressure should generally be $<130 / 80 \mathrm{~mm} \mathrm{Hg}$. 
Doi: 10.32481/djph.2021.12.017

\section{APPENDIX B}

Community Guide Systematic Review:

Changes in proportion of patients with controlled BP attributable to team-based care $^{32}$

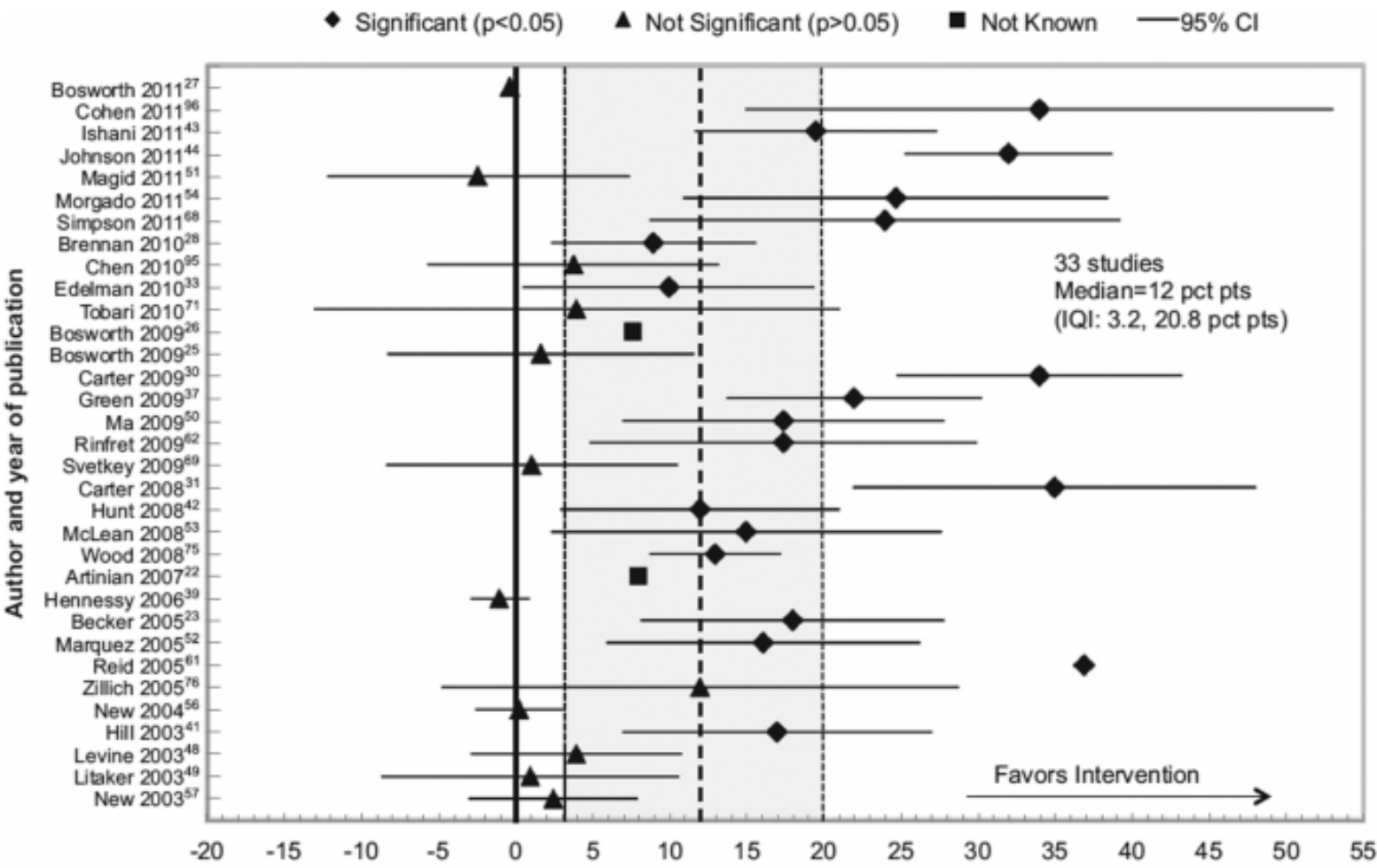

Absolute percentage point change $(95 \% \mathrm{Cl})$ in the proportion of patients with controlled blood pressure

\section{Sample Resources to Implement ACC/AHA CVD Primary Prevention Guidelines}

\begin{tabular}{|c|c|c|}
\hline ACC/AHA Guideline & Action & Resources \\
\hline $\begin{array}{l}\text { Prevent atherosclerotic } \\
\text { vascular disease, heart } \\
\text { failure, and atrial fibrillation } \\
\text { by promoting healthy } \\
\text { lifestyles throughout life }\end{array}$ & $\begin{array}{l}\text { Provide all patients with } \\
\text { information about heart } \\
\text { healthy programs }\end{array}$ & $\begin{array}{l}\text { - AHA: Be Healthy for } \\
\text { Good with Life's Simple } 7\end{array}$ \\
\hline $\begin{array}{l}\text { Use a team-based approach } \\
\text { to prevent CVD } \\
\text { Evaluate the social } \\
\text { determinants of health } \\
\text { (SDOH) that affect } \\
\text { individuals to inform } \\
\text { treatment decisions }\end{array}$ & $\begin{array}{l}\text { Collect race/ethnicity } \\
\text { from all patients. } \\
\text { Implement validated } \\
\text { SDOH screening tool }\end{array}$ & $\begin{array}{l}\text {-Quality Insights practice } \\
\text { module: } \underline{\text { Social }} \\
\text { Determinants of Health and } \\
\text { Workflow Modifications } \\
\text { - } \underline{\text { PRAPARE Toolkit }}\end{array}$ \\
\hline
\end{tabular}


Doi: 10.32481/djph.2021.12.017

\begin{tabular}{|c|c|c|}
\hline $\begin{array}{l}\text { Adults } 40-75 \text { years being } \\
\text { evaluated for CVD } \\
\text { prevention should undergo } \\
10 \text {-year risk estimation and } \\
\text { should have clinician-patient } \\
\text { risk discussion before } \\
\text { starting on pharmacological } \\
\text { therapy, such as } \\
\text { antihypertensive or statin }\end{array}$ & $\begin{array}{l}\text { Screen for risk factors and } \\
\text { apply race- and sex- } \\
\text { specific modifiers for } \\
\text { asymptomatic adults. } \\
\text { Manage hypertension and } \\
\text { blood cholesterol, use } \\
\text { clinical guidelines. Where } \\
\text { appropriate, assess risk } \\
\text { using coronary artery } \\
\text { calcium scanning }\end{array}$ & $\begin{array}{l}\text { - } \frac{\text { American College of }}{\text { Cardiology ASCVD Risk }} \\
\underline{\text { Estimator Tool }}\end{array}$ \\
\hline $\begin{array}{l}\text { Adults } 40-75 \text { years being } \\
\text { evaluated for CVD } \\
\text { prevention should undergo } \\
10 \text {-year risk estimation and } \\
\text { should have clinician-patient } \\
\text { risk discussion before } \\
\text { starting on pharmacological } \\
\text { therapy, such as } \\
\text { antihypertensive or statin }\end{array}$ & $\begin{array}{l}\text { Screen for risk factors and } \\
\text { apply race- and sex- } \\
\text { specific modifiers for } \\
\text { asymptomatic adults. } \\
\text { Manage hypertension and } \\
\text { blood cholesterol, use } \\
\text { clinical guidelines. Where } \\
\text { appropriate, assess risk } \\
\text { using coronary artery } \\
\text { calcium scanning }\end{array}$ & $\begin{array}{l}\text { - } \frac{\text { American College of }}{\text { Cardiology ASCVD Risk }} \\
\underline{\text { Estimator Tool }}\end{array}$ \\
\hline $\begin{array}{l}\text { All adults should consume a } \\
\text { healthy diet } \\
\text { For adults with overweight/ } \\
\text { obesity, comprehensive } \\
\text { lifestyle interventions, } \\
\text { including counseling and } \\
\text { caloric restrictions, are } \\
\text { recommended for achieving } \\
\text { and maintaining weight loss }\end{array}$ & $\begin{array}{l}\text { Provide all patients with } \\
\text { nutrition information } \\
\text { For patients with } \\
\text { hypertension, provide } \\
\text { DASH diet information } \\
\text { and promote self- } \\
\text { monitoring of blood } \\
\text { pressure } \\
\text { For patients with } \\
\text { overweight/ obesity, } \\
\text { administer prediabetes } \\
\text { risk tests and offer } \\
\text { information on weight } \\
\text { management } \\
\text { For patients with } \\
\text { prediabetes, refer to } \\
\text { National Diabetes } \\
\text { Prevention Program } \\
\text { (National DPP) }\end{array}$ & $\begin{array}{l}\text { - AHA's Life Simple } 7- \\
\text { Eat Better } \\
\text { - AHA: Life's Simple 7 - } \\
\text { Manage Weight } \\
\text { - Quality Insights: Take } \\
\text { Control of Hypertension } \\
\text { with WW and TOPS } \\
\text { - DASH Your Way to } \\
\text { Lower Blood Pressure } \\
\text { - Tips for Taking Your Own } \\
\text { Blood Pressure Readings } \\
\text { - CDC Prediabetes Risk } \\
\text { Test } \\
\text { Refer Your Patients with } \\
\text { Prediabetes to a National } \\
\text { DPP } \\
\text { CDC's Recognized } \\
\text { Lifestyle Change Programs }\end{array}$ \\
\hline $\begin{array}{l}\text { Adults should engage in at } \\
\text { least } 150 \text { min./week of } \\
\text { accumulated moderate- } \\
\text { intensity physical activity or }\end{array}$ & $\begin{array}{l}\text { Counsel all patients about } \\
\text { physical activity } \\
\text { recommendations. Provide } \\
\text { educational materials. }\end{array}$ & - $\frac{\text { AHAs Life's Simple } 7-}{\underline{\text { Move More }}}$ \\
\hline
\end{tabular}


Doi: 10.32481/djph.2021.12.017

\begin{tabular}{|c|c|c|}
\hline $\begin{array}{l}75 \mathrm{~min} . / \text { week of vigorous- } \\
\text { intensity physical activity. }\end{array}$ & & \\
\hline $\begin{array}{l}\text { For adults with type } 2 \\
\text { diabetes mellitus, lifestyle } \\
\text { changes, such as improving } \\
\text { dietary habits and achieving } \\
\text { exercise recommendations, } \\
\text { are crucial. }\end{array}$ & $\begin{array}{l}\text { Refer patients to Diabetes } \\
\text { Self-Management } \\
\text { Education and Support } \\
\text { (DSMES). }\end{array}$ & 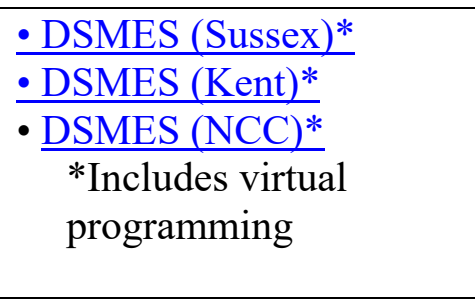 \\
\hline $\begin{array}{l}\text { All adults should be assessed } \\
\text { at every healthcare visit for } \\
\text { tobacco use, and those who } \\
\text { use tobacco should be } \\
\text { assisted and strongly advised } \\
\text { to quit. }\end{array}$ & $\begin{array}{l}\text { Ask every patient about } \\
\text { tobacco use. Provide } \\
\text { cessation assistance. }\end{array}$ & $\begin{array}{l}\text {-AHA: Life's Simple } 7- \\
\underline{\text { How to Quit Tobacco }} \\
\text { - } \underline{\text { Delaware QuitLine }}\end{array}$ \\
\hline $\begin{array}{l}\text { Aspirin should be used } \\
\text { infrequently in routine } \\
\text { primary prevention of } \\
\text { ASCVD because of lack of } \\
\text { net benefit. }\end{array}$ & $\begin{array}{l}\text { Evaluate use of aspirin } \\
\text { therapy based on patient } \\
\text { age and risk-enhancing } \\
\text { factors such as family } \\
\text { history, ability to achieve } \\
\text { lipid, BP, or glucose } \\
\text { targets. }\end{array}$ & $\begin{array}{l}\cdot \frac{2019 \text { ACC/AHA }}{\text { Guideline on the }} \\
\underline{\text { Primary Prevention of }} \\
\text { Cardiovascular Disease }\end{array}$ \\
\hline $\begin{array}{l}\text { Statin therapy is first-line } \\
\text { treatment for primary } \\
\text { prevention of ASCVD in } \\
\text { patients with elevated LDL- } \\
\text { C, those with diabetes who } \\
\text { are age } 40-75 \text {, and those at } \\
\text { sufficient ASCVD risk after } \\
\text { clinician-patient risk } \\
\text { discussion. }\end{array}$ & $\begin{array}{l}\text { Assess LDL-C and related } \\
\text { risk factors. Initiate } \\
\text { risk/benefit discussion. }\end{array}$ & $\begin{array}{l}\frac{\text { - } 2018 \text { Guideline on the }}{\text { Management of Blood }} \\
\text { Cholesterol } \\
\text { - Statin Choice Decision } \\
\underline{\text { Aid }} \text { - } \underline{\text { Adherence Estimator }(})\end{array}$ \\
\hline $\begin{array}{l}\text { Nonpharmacological } \\
\text { interventions are } \\
\text { recommended for all adults } \\
\text { with elevated BP or HTN. } \\
\text { For those requiring } \\
\text { pharmacological therapy, } \\
\text { target BP should generally } \\
\text { be }<130 / 80 \mathrm{~mm} \mathrm{Hg} \text {. }\end{array}$ & $\begin{array}{l}\text { Assess BP for all patients } \\
\text { and recommend evidence- } \\
\text { based lifestyle programs } \\
\text { where appropriate. }\end{array}$ & - $\frac{\text { Million Hearts } \AA}{\text { Hypertension Control }}$ \\
\hline
\end{tabular}




\section{References}

1. Korowynk, C., McCormack, J., Kolber, M. R., Garrison, S., \& Allan, G. M. (2017). Competing demands and opportunities in primary care. Canadian Family Physician. https://www.ncbi.nlm.nih.gov/pmc/articles/PMC5597006/

2. Centers for Disease Control and Prevention. (2020). Heart disease facts. https://www.cdc.gov/heartdisease/facts.htm

3. Delaware Health and Social Services. (2019). Chronic disease in Delaware: Facts and figures. https://dhss.delaware.gov/dhss/dph/dpc/files/2019chronicdiseasefactsfigures.pdf

4. Arnett, D. K., Khera, A., \& Blumenthal, R. S. (2019, October 1). 2019 ACC/AHA guideline on the primary prevention of cardiovascular disease. JAMA Cardiology, 4(10), 1043-1044. PubMed https://doi.org/10.1001/jamacardio.2019.2604

5. Egan, B. M., Sutherland, S. E., Rakotz, M., Yang, J., Hanlin, R. B., Davis, R. A., \& Wozniak, G. (2018, December). Improving hypertension control in primary care with the Measure Accurately, Act Rapidly, and Partner with Patients protocol. Hypertension, 72(6), 1320-1327. Retrieved from https://www.ncbi.nlm.nih.gov/pmc/articles/PMC6221423/pdf/hyp-72-1320.pdf PubMed https://doi.org/10.1161/HYPERTENSIONAHA.118.11558

6. Delaware Health and Social Services, Division of Public Health. (2019). Update on high cholesterol data. https://www.dhss.delaware.gov/dhss/dph/dpc/cholesterol_update.html

7. Coleman, K., Wagner, E., Schaefer, J., Reid, R., \& LeRoy, L. (2016). Redefining primary care for the $21^{\text {st }}$ century. Agency for Healthcare Research and Quality. https://www.ahrq.gov/ncepcr/primary-care-research/workforce-financing/white-paper.html

8. Schottenfeld, L., Petersen, D., Peikes, D., Ricciardi, R., Burak, H., McNelis, R., \& Genevro, J. (2016). Creating patient-centered team-based primary care. Agency for Healthcare Research and Quality. https://pcmh.ahrq.gov/page/creating-patient-centered-team-basedprimary-care

9. American Medical Association. (2019). Physician-led team-based care. https://www.amaassn.org/practice-management/payment-delivery-models/physician-led-team-based-care

10. MacColl Center for Health Care Innovation. (2015). Improving primary care team guide. http://improvingprimarycare.org/

11. Smith, C., Balatbat, C., Corbridge, S., Dopp, A., Fried, J., Harter, R., . . Sinsky, C. (2018). Implementing optimal team-based care to reduce clinician burnout. National Academy of Medicine Perspectives. https://nam.edu/implementing-optimal-team-based-care-to-reduceclinician-burnout/

12. New England Journal of Medicine Catalyst. (2017). What is patient-centered care? https://catalyst.nejm.org/doi/full/10.1056/CAT.17.0559

13. Tsai, C. H., Eghdam, A., Davoody, N., Wright, G., Flowerday, S., \& Koch, S. (2020, December 4). Effects of electronic health record implementation and barriers to adoption and use: A scoping review and qualitative analysis of the content. Life (Basel, Switzerland), 10(12), 327. PubMed https://doi.org/10.3390/life10120327 
14. Virani, S. S., Alonso, A., Benjamin, E. J., Bittencourt, M. S., Callaway, C. W., Carson, A. P., .... Tsao, C. W., \& the American Heart Association Council on Epidemiology and Prevention Statistics Committee and Stroke Statistics Subcommittee. (2020, March 3). Heart disease and stroke statistics - 2020 update: A report from the American Heart Association. Circulation, 141(9), e139-e596. Retrieved from https://www.ahajournals.org/doi/10.1161/CIR.0000000000000757 PubMed

15. Krist, A. H., Davidson, K. W., Mangione, C. M., Barry, M. J., Cabana, M., Caughey, A. B., . ... Wong, J. B., \& the US Preventive Services Task Force. (2020, November 24). Behavioral counseling interventions to promote a healthy diet and physical activity for cardiovascular disease prevention in adults with cardiovascular risk factors. U.S. Preventive Services Task Force recommendation sheet. JAMA, 324(20), 2069-2075. PubMed

16. U.S. Department of Health and Human Services. (2020). Smoking cessation. A report of the Surgeon General. https://www.hhs.gov/sites/default/files/2020-cessation-sgr-full-report.pdf

17. Centers for Disease Control and Prevention. (2020). Social determinants of health. https://www.cdc.gov/socialdeterminants/index.htm

18. McGovern, L., Miller, G., \& Hughes-Cromwick, P. (2014). What determines how healthy you are? Robert Wood Johnson Foundation. https:/www.rwjf.org/en/library/research/2014/08/the-relative-contribution-of-multipledeterminants-to-health-out.html

19. Angell, S. Y., McConnell, M. V., Anderson, C. A., Bibbins-Domingo, K., \& Boyle, D. S. Captewell, ... \& Warner, J.J. (2020). The American Heart Association 2030 impact goal: A presidential advisory from the American Heart Association. Circulation, 141(8). https://www.ahajournals.org/doi/epub/10.1161/CIR.0000000000000758

20. American Medical Association. (2015). Why race, ethnicity and language data is crucial to quality care. https://www.ama-assn.org/delivering-care/patient-support-advocacy/why-raceethnicity-and-language-data-crucial-quality-care

21. Weir, R. C., \& Jester, M. (2018). Addressing the relationship between social determinants of health and outcomes: Findings from the PRAPARE pilot. National Association of Community Health Centers. http://www.nachc.org/wp-content/uploads/2019/01/PRAPAREData-Findings-HIgh-Risk-General-slides-for-Toolkit.pdf

22. American Hospital Association. (2019). Social determinants of health. 2019. https://www.aha.org/system/files/2018-04/value-initiative-icd-10-code-social-determinantsof-health.pdf

23. Wall, H. K., Hannan, J. A., \& Wright, J. S. (2014). Patients with undiagnosed hypertension: Hiding in plain sight. Journal of the American Medical Association. https://jamanetwork.com/journals/jama/fullarticle/1935131

24. Community Preventive Services Task Force. (2014). Team-based care to improve blood pressure control. Journal of Preventive Medicine. https://www.thecommunityguide.org/sites/default/files/publications/cvd-AJPM-recs-teambased-care.pdf 
25. Centers for Disease Control and Prevention. (2020). Self-measured blood pressure monitoring with clinical support. https://www.cdc.gov/dhdsp/pubs/guides/bestpractices/smbp.htm

26. Centers for Disease Control and Prevention. (2020). Million Hearts ${ }^{\circledR}$ hypertension control change package, $2^{\text {nd }}$ edition. https://millionhearts.hhs.gov/tools-protocols/action-guides/htnchange-package/index.html

27. Mayo Foundation for Medical Education and Research. (n.d.). Statin choice decision aid. https://statindecisionaid.mayoclinic.org/

28. Centers for Disease Control and Prevention. (2016). Million Hearts ${ }^{\circledR}$ medication adherence action steps for public health practitioners. https://millionhearts.hhs.gov/files/MedicationAdherence-Action-Guide-for-PHPs.pdf

29. Merck. (2020). Use the adherence estimator. Adherence Estimator ${ }^{\circledR}$. https://www.adherenceestimator.com/default.aspx

30. Delaware Health and Social Services and Quality Insights. (2020). Medication therapy management: Evidence-based collaboration to improve blood pressure control. https://qualityinsights.org

31. Arnett, D. K., Khera, A., \& Blumenthal, R. S. (2019, October 1). 2019 ACC/AHA guideline on the primary prevention of cardiovascular disease. JAMA Cardiology, 4(10), 1043-1044. PubMed https://doi.org/10.1001/jamacardio.2019.2604

32. Proia, K. K., Thota, A. B., Njie, G. J., Finnie, R. K. C., Hopkins, D. P., Mukhtar, Q., . .. Cooksey, T., \& the Community Preventive Services Task Force. (2014, July). Team-based care and improved blood pressure control: A community guide systematic review. American Journal of Preventive Medicine, 47(1), 86-99. PubMed

Copyright (c) 2021 Delaware Academy of Medicine / Delaware Public Health Association.

This is an Open Access article distributed under the terms of the Creative Commons Attribution Non-Commercial License (https://creativecommons.org/licenses/by-nc-nd/4.0/) which permits unrestricted non-commercial use, distribution, and reproduction in any medium, provided the original work is properly cited. 